\title{
Perception of Mothers Needs and Nurses Felt Needs on Nursing Care Provided by Nurses to their Neonates in the Neonatal Intensive Care Unit
}

\author{
Neema Bhandari ${ }^{1}$, Satya Shrestha ${ }^{1}$, Srijana Dongol $^{1}$, Basanti Bal ${ }^{2}$ \\ ${ }^{1}$ Kathmandu University School of Medical Sciences, ${ }^{2}$ Kathmandu University Hospital, Dhulikhel, Kavre, \\ Nepal
}

\section{Correspondence}

Ms Neema Bhandari

Kathmandu University School

of Medical Sciences

Dhulikhel, Kavre, Nepal

\section{Email:}

neemakusms@yahoo.com

DOI: http://dx.doi.org/10.3126/ jcmsn.v13i4.18036

Orcid ID: orcid.org/0000-0002 $-5351-959 \mathrm{X}$

Article received: Aug $14^{\text {th }} 2017$ Article accepted: Nov $24^{\text {th }} 2017$

\begin{abstract}
Background \& Objectives: Nurses play an important role in helping parents by developing therapeutic relationship, providing accurate and proper information, emotional support, giving assurance, providing comfort and allowing parents to provide care to neonates under supervision in Neonatal Intensive Care Unit (NICU). The objective of the study was to assess the perception of mothers needs and nurses felt needs on nursing care provided by nurses to their neonates in the NICU. Materials \& Methods: This was descriptive cross-sectional study conducted in 21 NICU nurses and 69 mothers whose neonates were admitted in the NICU. Data were collected for a period of six months. Data were gathered using opinion-survey Likert scale and were analyzed using descriptive-analytical methods. Results: Subscales related to family needs, the mean score $( \pm \mathrm{SD})$ of mothers in information was 37.7 \pm 3.8 , in comfort $32.1 \pm 2.8$, in support $38.8 \pm 3.4$, in assurance $31.2 \pm 2.2$, in proximity $21.7 \pm 2.8$. Mean score on care provided by nurses to their neonates in information need $39.0 \pm 3.6$, in comfort $31.5 \pm 2.9$, in support $38.8 \pm 4.1$, in assurance $30.2 \pm 3.0$, in proximity $21.1 \pm 2.4$. There was no statistical difference shown in the study. The study shows positive correlation between mother's perceived need and nurses felt needs. Conclusion: According to the study findings, nurses don't put subjective assumption over mothers need. So, to develop nursing care plan, it is important to understand the needs perceived by the mothers.
\end{abstract}

Key words: Needs; Neonatal Intensive Care Unit; neonates

Citation: Bhandari N, Shrestha S, Dongol S, Bal B. Perception of Mothers Needs and Nurses Felt Needs on Nursing Care Provided by Nurses to their Neonates in the Neonatal Intensive Care Unit.. JCMS Nepal. 2017;13(4):406-9.

\section{INTRODUCTION}

In Nepal, in the fiscal year $2014 / 2015$, a total of 32,109 (0-28) days' infants were treated at health facilities and PHC / ORC clinics. ${ }^{1}$ The birth of a baby is supposed to be a happy event, but for parents with a infant in the NICU, it is marked by fear, sadness, guilt and anger. ${ }^{2}$ Many infants admitted to the NICU are born premature and have low birth weight or a medical conditions that requires intensive medical and nursing care, sometimes for several months following birth. ${ }^{3}$

So, the need of proper information, support, comfort, assurance, and proximity are very important to be addressed while planning a nursing care plan. Parents experience communication with the NICU staff as essential to the management of their situation. ${ }^{4}$ When parents receive information, they feel less anxious and have a better relationship with staff..$^{5}$ It is very important that nurses should provide the concrete information in order to better understand parents' need for support and try to meet their expectations, resulting in improved nursing care in neonatal intensive care units. ${ }^{6}$ If nurses provide emotional support to parents, promote family presence and participation in the NICU and can create a welcoming environment for families which is a part of the family-centered care. ${ }^{7}$ Assurance to parents in the NICU can enhance nursing communication and allow nurses to incorporate parents needs into families care plan. ${ }^{8}$ 
Parents need assurance and proximity through confidence in the care provided to their child and involvement in decision-making and care giving activities. ${ }^{3}$ A competent nurse has the confidence to successfully navigate and manage the most challenging situations while continuing to view the patient in a holistic manner. ${ }^{5}$

Parents especially mother's need must be understood by the nurses to provide quality care to the neonates who is admitted in the NICU, to provide quality care. Determining mother's most and least important needs allow nurses to define actual needs in NICU. The objective of the study was to assess the perception of mothers needs and nurses felt needs on nursing care provided by nurses to their neonates in the NICU.

\section{MATERIALS AND METHODS}

A descriptive cross-sectional study was carried out using non-probability, consecutive sampling technique. Respondents were mothers whose neonates were admitted in NICU, 48 hours before and were stable during data collection period and those nurses who worked in NICU of Kathmandu University Hospital at least six weeks prior to the data collection. The data were collected between $1 \mathrm{st}$ September 2016 to $28^{\text {th }}$ February 2017. Data were collected by pre-tested, predesigned five-points Likert scale both for mothers and nurses. Validity was ensured by extensive literature search and consulting with colleague. Data collection tool was translated in to Nepali version for mothers and English version for nurses after changing verbs. The Likert-scale had 40 items to measure mothers perceived needs and nurses felt needs under five categories such as information, comfort, support, assurance and proximity. Items were rated on 5point Likert type scale ranging from $1=$ not important to $5=$ very important.

After getting written approval from the Institutional Review Committee, Kathmandu University School of Medical Sciences (IRC-KUSMS). Mothers were contacted when they visited their neonates in NICU. Written consent was taken from the mothers who participated in the study. Items were read aloud to the mothers and the mothers were given sufficient time to think and to rate the statements as not important to very important. After taking written consent from nurses to participate in the study, they were provided the questionnaire. Both mothers and nurses were assured of confidentiality and anonymity.
Data analysis was done using Statistical Package for the Social Sciences (SPSS) version 16, frequency and percentage were calculated. The highest score was 200 and lowest 40 for both mothers and nurses to score the perceived and felt needs. T-test was performed in order to find a gap between mothers' perceived needs and nurses felt needs.

\section{RESULTS}

Out of 69 mothers who were enrolled in the study, the neonate born to them were had a mean gestational age of 37.3 weeks. The mean hospital stay of the neonate was 5.8 days and mean weight was $2.3 \mathrm{~kg}$. The number of male neonate was 48 $(69.5 \%)$. The number of nurses who participated in the study was 21 and their experiences varied from six months to seven years.

\section{DISCUSSION}

The findings of present study demonstrate the perception of mothers needs and nurses felt needs on nursing care provided by nurses to their neonates in the neonatal intensive care unit.

Statistical analysis of the study showed that there was no difference in mothers perceived needs and nurses felt needs.

This study reveals that the mean score of mothers in different needs like in information was $37.7 \pm 3.8$, in comfort $32.1 \pm 2.8$, in support $38.8 \pm 3.4$, in assurance $31.2 \pm 2.2$, and in proximity $21.7 \pm 2.8$. Similarly, mean score of nurses in different needs in information was $39 \pm 3.6$, in comfort $31.5 \pm 2.9$, in support $38.8 \pm 4.1$, in assurance $30.2 \pm 3$, and in proximity $21.1 \pm 2.4$ respectively.

This shows that the mothers' perceived needs have been fully understood by the nurses and the mothers are highly satisfied by the care provided by nurses to their neonates in the NICU. This is supported by the study conducted by Joseph $\mathrm{AM}^{9}$ where mothers rated information need as $(89.07 \%)$, comfort area with mean \pm SD of $12.73 \pm 1.47$, assurance area with mean \pm SD of $9.55+1.89$, proximity with mean \pm SD of $7.53 \pm+1.26$. In his study the mothers perceived health care needs as the most important and were highly satisfied with the care provided to their neonates by nurses.

Unlike Joseph $\mathrm{AM}^{9}$, there are many studies which are contrasted to this study's findings. In this regard, Aemmi $\mathrm{Z}$ et $\mathrm{al}^{10}$ found that mothersproximity $(95.3 \%)$, assurance $(94.1 \%)$, information (91.1\%), support $(79.7 \%)$ and comfort $(72.8 \%)$. 
Table: 1 Mean and standard deviation related to needs among mothers and nurses

$\begin{array}{llll}\text { Needs } & \text { Mean } & \text { Std. deviation } & \text { p-value } \\ \text { Information } & & 3.8 & 0.162 \\ \quad \text { Mothers }(\mathrm{n}=69) & 37.7 & 3.6 & \\ \quad \text { Nurses(n=21) } & 39.0 & & 0.425 \\ \text { Comfort } & & 2.8 & \\ \quad \text { Mothers }(\mathrm{n}=69) & 32.1 & 2.9 & 0.925 \\ \quad \text { Nurses }(\mathrm{n}=21) & 31.5 & & \\ \text { Support } & & 3.4 & \\ \text { Mothers }(\mathrm{n}=69) & 38.8 & 4.1 & 0.099 \\ \text { Nurses }(\mathrm{n}=21) & 38.8 & & \\ \text { Assurance } & & 2.2 & \\ \text { Mothers }(\mathrm{n}=69) & 31.2 & 3.0 & 0.316 \\ \text { Nurses }(\mathrm{n}=21) & 30.2 & & \\ \text { Proximity } & & 2.8 & \\ \text { Mothers }(\mathrm{n}=69) & 21.7 & 2.4 & \\ \text { Nurses(n=21) } & 21.1 & & \end{array}$

Nurses believed that the following items were the most important needs of the mothers: assurance $(80.3 \%)$, proximity $(75.2 \%)$, information $(70.8 \%)$, comfort $(66.3 \%)$ and support $(64.8 \%)$. Vaskelyte $\mathrm{A}^{11}$ concluded that the majority of statistically significant differences between parents and nurses were assessing the proximity (75\%) and information $(72.7 \%)$ needs. Parents, if compared to nurses rated these needs as more important. The assessment of support needs showed the lowest number of differences $(38.9 \%)$.

In the study by Lam $\mathrm{J}^{15}$ if there was high level of support from nurses, then there would be low level of stress perceived by the neonates' families. Sikorova and Kucova $\mathrm{J}^{12}$ conducted study where mothers evaluated the support of nursing staff in most of these areas as high. In the another study also mothers rated all nursing support items as important comparatively emotional support was rated less important. ${ }^{13}$

Parents' emotional and psychological needs should be considered by the nurses while providing care to the neonates. ${ }^{15}$ Here, mothers scores every subscale was lower than nurses who cared for them and their children regarding nursing support. ${ }^{6}$ Parents rated assurance-type needs as the highest ${ }^{8}$ supporting- emotional needs of parents of premature infants admitted in NICU. ${ }^{14}$ In a study, parents wished for proximity to infant and contacted with them. ${ }^{5}$ Mothers felt confident when they were allowed proximity to their neonates, and they wished that was considered by the nurses. ${ }^{16}$

\section{CONCLUSION}

A complete health care of neonates admitted at the hospital is possible with a proper match between mothers' perceived needs and nurses' felt needs in their nursing care delivery. At this backdrop, the study concludes that there is no statistical difference between mothers' perceived needs and nurses' felt needs in NICU of Kathmandu University Hospital. This posits a positive correlation between their needs which shows that there is a quality care of neonates.

\section{REFERENCES}

1. Annual Report. Department of Health Services. Nepal. 2014/2015

2. Grosik C, Snyder D, Cleary GM, Breckenridge DM, Tidwell B. Identification of Internal and External Stressors in Parents of Newborns in Intensive Care. The Permanente J.2013; 17(3):36-41. https://doi.org/10.7812/TPP/12-105. PMID: 24355889.

3. Feeley N, Waitzer E, Sherrard K, Boisvert L. Zelkowitz P. 
Fathers'perceptions of the barriers and facilitators to their involvement with their newborn hospitalized in the neonatal intensive care unit. $\mathbf{J}$ of clin nurs. 2013;22(34):521-30. https://doi.org/10.1111/j.13652702.2012.04231.x. PMID: 23186388.

4. Wigert H, Blom MD, Bry K. Parents experiences of communication with neonatal intensive-care unit staff: an interview study. BMC Pediatrics. 2014;14:304. https:// doi.org/10.1186/s12887-014-0304-5. PMID: 25492549.

5. Victoria V \& Xiaomei C. Parenting the NICU infant: A meta-ethnographic synthesis. International $\mathrm{J}$ of Nurs science. 2014:281-90.

6. Valizadeh L, Zamanzadeh V, Akbarbegloo M, Sayadi L. Importance and Availability of support for Mothers in NICU: A comparision of opinions of Irian Mothers and Nurses, Iran J Pediatr.2012;12(2):191-96

7. Cleveland LM. Parenting in the neonatal Intensive care Unit. J obstet Gynecol Neonatal Nurs. 2008;37:666-91. https://doi.org/10.1111/j.1552-6909.2008.00288.x. PMID: 19012717.

8. Cynthia AM. Assessment of family Needs in Neonatal Intensive care units. Ame J of Critical care.2010;19(2):15663. https://doi.org/10.4037/ajcc2010130. PMID: 20194612.

9. Joseph AM. A correlative study to assess the perceived needs and satisfaction of care among mothers of neonates admitted in NICU in a selected Hospital at Mangalore. Int. J. Nurs. Edu and Research.2015;3(4):382-92. https:// doi.org/10.5958/2454-2660.2015.00028.9.

10. Aemmi Z, Ahmadi Z, Reyhani J, Haghani H. Comparision of Perceptions of Nurses and Premature Infants' Mothers about Mothers, needs in Neonatal Intensive care unit. Hayat, J of School of Nurs and Midwifery, Tehran Uni of Med Sci. 2013;19(2):14-26.

11. Vaskelyte A, Butkeviciene R. needs of parents with premature newborns in the Neonatal Intensive Care Unit: parents' anD nurses' perceptions. Medicina (Kaunas). 2010;46(1): 43-53.

12. Sikorova 1, Kucova J. The need of mothers to newborns hospitalizes in intensive care units. Biomed Pap Med Fac univ palacky Olomouc Crech Repub. 2012;156(4):330-6.

13. Mok E, Leung SF. Nurses as providers of support for mothers of premature infants. J of cli Nurs. 2006;15(6):726 -34. https://doi.org/10.1111/j.1365-2702.2006.01359.x. PMID: 16684168.

14. Aliabadi F, Kamali M, Borimnejad L, Rassafiani M, Rasti M, Shafaroodi N, et al. Supporting-emotional needs of Iranian parents with premature infants admitted to Neonatal Intensive care Unit. Med J. Islam Repub Iran. 2014;28:53. PMID: 25405119

15. Lam J, Spence K, Halliday R. Parents perception of nursing $g$ support in the neonatal intensive care unit (NICU). Neonatal Paed and Child Health Nurs. 2007;10(3).

16. Obeidat HM, Bond EA, Callister LC. The Parental Experience of Having an Infant in the Newborn Intensive Care Unit. The J of Parental Edu. 2009;18(3):23-29. https:// doi.org/10.1624/105812409X461199. 